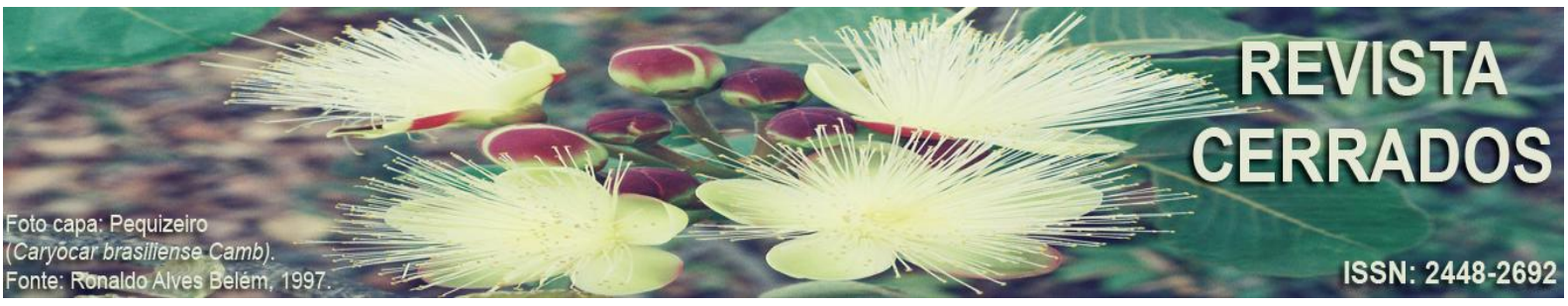

\title{
REFLEXÕES SOBRE TERRITÓRIO E EDUCAÇÃO QUILOMBOLA: tensões e resistências
}

\section{REFLECTIONS ON TERRITORY AND QUILOMBOLA EDUCATION: tensions and resistance}

\section{REFLEXIONES SOBRE TERRITORIO Y EDUCACIÓN QUILOMBOLA: tensiones y resistencias}

\author{
Carlos Alberto de Souza Mascarenhas \\ Universidade Federal do Pará - UFPA \\ E-mail: <profgeografiacarlos@hotmail.com>.
}

\begin{abstract}
Resumo
Examinamos a relação entre território e educação quilombola, considerando educação como política territorial para as populações no espaço agrário amazônico. Focalizou-se uma situação empírica, o quilombo de África e Laranjituba no município de Moju (PA) para expor tensões e resistências. O objetivo é mostrar como essas políticas desconsideram educação e território como indissociáveis e fundamentais para modificar as condições precárias de existência e que essa situação deve ser entendida articulando interesses de agentes em diferentes escalas geográficas. $\mathrm{O}$ percurso metodológico passa pela revisão bibliográfica, por pesquisas em sites das prefeituras do Moju (PA), Abaetetuba (PA), e da Secretaria Executiva de Educação (SEDUC) do Pará, bem com no Instituto de Terras do Pará (ITERPA), pelo uso de entrevistas e questionários com perguntas semiestruturadas. As políticas educacionais ignoraram as experiências dessas populações e impediram o ingresso em níveis elevados de escolaridade.
\end{abstract}

Palavras-chave: Território; Educação; Quilombo.

\begin{abstract}
We examine the relationship between territory and quilombola education, considering education as territorial policy for the populations in the Amazonian agrarian space. An empirical situation was focused, the quilombo of Africa and Laranjituba in the municipality of Moju (PA) to expose tensions and resistances. The objective is to show how these policies disregard education and territory as inseparable and fundamental to modify the precarious

Revista Cerrados, Departamento de Geociências e Programa de Pós-Graduação em Geografia (UNIMONTES)
\end{abstract}


conditions of existence and that this situation must be understood articulating interests of agents in different geographic scales. The methodological approach is the bibliographical review, through researches on sites of Moju (PA), Abaetetuba (PA), and the Executive Secretariat of Education (SEDUC) of Pará, as well as in the Land Institute of Pará (ITERPA). use of interviews and questionnaires with semi-structured questions. Educational policies ignored the experiences of these populations and prevented them from entering high levels of schooling.

Keywords: Territory; Education; Quilombo.

\section{Resumen}

Examinamos la relación entre territorio y educación quilombola, considerando educación como política territorial para las poblaciones en el espacio agrario amazónico. Se enfocó una situación empírica, el quilombo de África y Laranjituba en el municipio de Moju (PA) para exponer tensiones y resistencias. El objetivo es mostrar cómo esas políticas desconsideran educación y territorio como indisociables y fundamentales para modificar las condiciones precarias de existencia y que esa situación debe ser entendida articulando intereses de agentes en diferentes escalas geográficas. El recorrido metodológico pasa por la revisión bibliográfica, por investigaciones en sitios de las alcaldías de Moju (PA), Abaetetuba (PA), y de la Secretaría Ejecutiva de Educación (SEDUC) de Pará, así como en el Instituto de Tierras de Pará (ITERPA) el uso de entrevistas y cuestionarios con preguntas semiestructuradas. Las políticas educativas ignoraron las experiencias de esas poblaciones e impidieron el ingreso en niveles elevados de escolaridad.

Palabras clave: Territorio; Educación; Quilombo.

\section{INTRODUÇÃO}

O planejamento das políticas educacionais e sua execução nos territórios quilombolas não contribuiu para a superação da dificuldade de acesso, permanência e respeito às singularidades culturais. As escolas em territórios quilombolas sofrem com a deterioração física e com processos educacionais alheios às suas especificidades culturais. A reflexão centra-se na relação entre território e educação quilombola, isto é, a educação como política territorial elaborada pelo Estado para quilombolas compromete as condições de existência do lugar. O objetivo é mostrar como essas políticas desconsideram a existência espacial quilombola e constituem um instrumento de interesses de agentes em diferentes escalas para intensificar o uso desigual do território. 
Elegeu-se o quilombo de África e Laranjituba pela situação de exclusão social, invisibilidade e desconhecimento do território quanto às políticas de educação. Localizado na zona rural dos municípios de Abaetetuba (PA) e Moju (PA), no quilômetro 68 da Rodovia Alça Viária, ramal Caeté (mapa 1), distante cerca de 33 km de Barcarena (PA), 42 km de Abaetetuba (PA) e $44 \mathrm{~km}$ de Moju (PA), o quilombo foi titulado em 2008 pelo Instituto de Terras do Pará (ITERPA) com uma área de 1.108, 18 ha e 48 famílias ${ }^{1}$.

Mapa 1 - Localização do Território Quilombola em Moju e Abaetetuba - PA

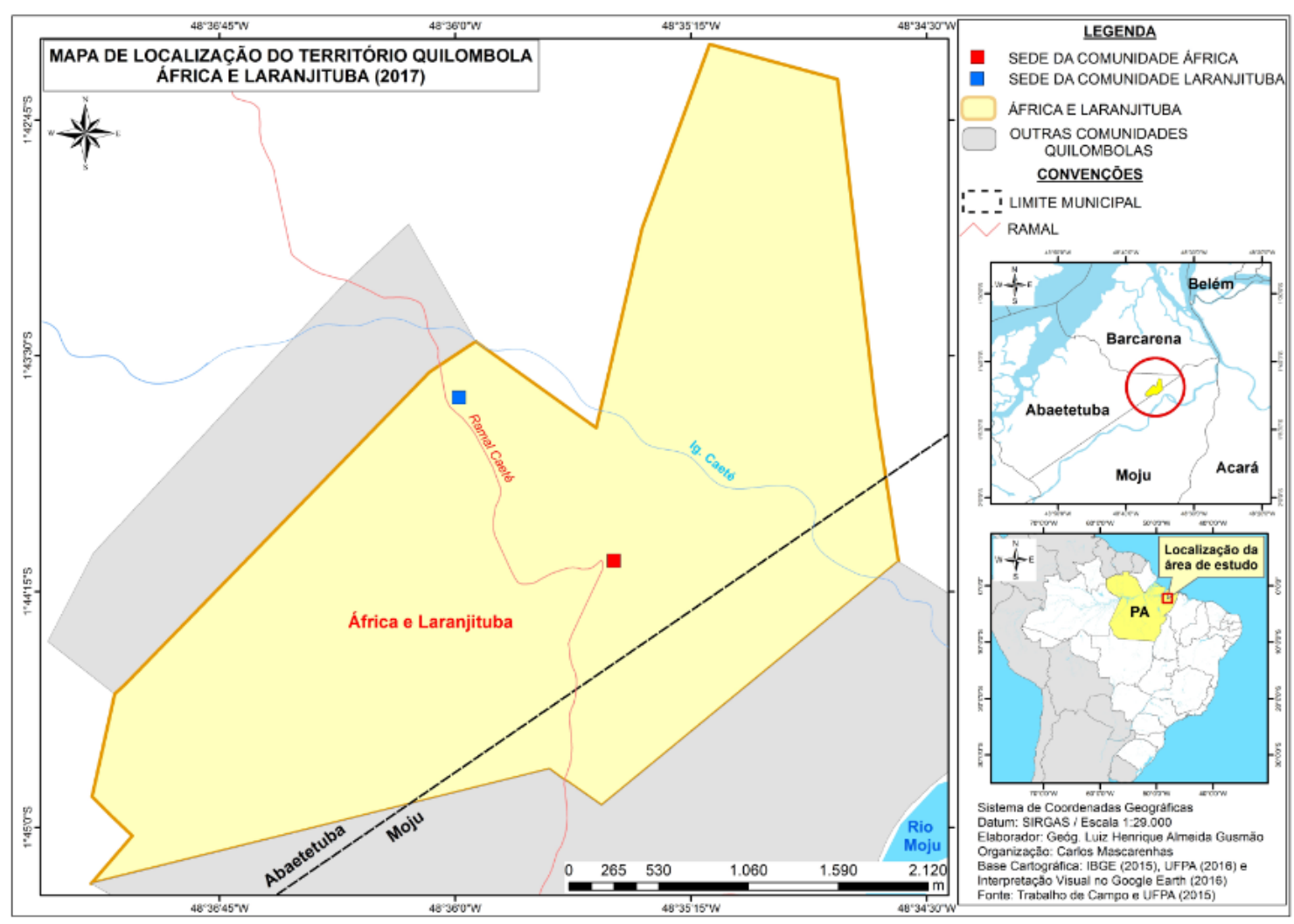

Fonte: Organizado pelos autores, Out/2016. Pesquisa de campo.

Atualmente possui um total de 193 habitantes, 82 na comunidade de África e 111 na de Laranjituba, distribuídos em 72 famílias. Marcam a paisagem do quilombo 59 residências de madeira, 10 de alvenaria e 3 mistas (alvenaria e madeira), sendo que 61 famílias dispõe de abastecimento de água encanada do Programa Raízes lançado em 2000, 9 utilizam água de poço e igarapé e 2 de igarapé, não existe coleta de lixo domiciliar e esgotamento sanitário nas comunidades do quilombo e nem posto de saúde. Duas escolas ajudam a compor a configuração espacial do lugar, uma de alvenaria (escola Bento Lima) em

\footnotetext{
${ }^{1}$ Informações disponíveis em http://www.iterpa.pa.gov.br/content/quilombolas. Acesso em: 06 set. 2017
} 
África, onde funciona o ensino médio modular nos três turnos e outra em Laranjituba (escola Baixo Caeté) também de alvenaria que oferece o ensino fundamental menor.

Nesse debate, concordando com os teóricos que discutem espaço, território e identidade territorial, pensar "campo como território (...) significa compreendê-lo como espaço de vida, ou como um tipo de espaço geográfico onde se realizam todas as dimensões da existência humana" (FERNANDES, 2006, p. 28-29). Entende-se espaço como "um instrumento político intencionalmente manipulado (...), a representação do espaço sempre serviria a uma estratégia, sendo ao mesmo tempo abstrata e concreta, pensada e deseja, isto é, projetada" (LEFEBVRE, 2016, p. 44). E compreender "identidade territorial como identidade social definida fundamentalmente através do território, ou seja, dentro de uma relação de apropriação que se dá tanto no campo das ideias como na realidade concreta" (HAESBAERT, 1999, p. 172) como categorias fundamentais que formam a base da reflexão acerca da educação em território quilombola.

Definiu-se a metodologia da seguinte forma: revisão bibliográfica, pesquisas em sites das prefeituras do Moju (PA), Abaetetuba (PA), e da Secretaria Executiva de Educação (SEDUC) do Pará, bem com do Instituto de Terras do Pará (ITERPA), sendo que a página oficial do Moju não havia disponibilizado o Plano de Municipal da Educação - PME e não foi possível se deslocar até a cidade para solicitar o documento pelas limitações de gastos.

Os dados primários em pesquisa de campo foram coletados utilizando questionários e entrevistas abertas contendo perguntas semiestruturadas com lideranças das comunidades, com a Defensoria Pública, com alunos, pais de alunos e professores. O questionário definiu um roteiro de perguntas capaz de traduzir os objetivos em questões específicas sobre políticas públicas e educação no território quilombola e a entrevista objetivou obter informações para confrontar as políticas públicas educacionais implantadas no território quilombola e o atendimento de suas demandas, articulando a problemática da educação pública e as demandas do território quilombola num contexto de redefinição de limites municipais que afeta a identidade territorial dessa população.

Do universo de 72 famílias do quilombo de África e Laranjituba, 22 foram entrevistadas. Das outras 18 comunidades afetadas pela redefinição de limites municipais, selecionamos 1 representante de Camorituba-Beira, Aguapé, Anapu, Moju-miri, e entrevistamos o Defensor público responsável pelo acompanhamento do caso. As entrevistas 
foram realizadas nos dias 10, 11 e 12 de junho de 2017. Essa perspectiva proporcionou um roteiro mais flexível e permitiu melhor acesso ao conteúdo dos diálogos.

$\mathrm{O}$ artigo está estruturado em três partes: inicialmente, são apontadas políticas de redefinição de limites municipais entre os municípios de Moju (PA), Abaetetuba (PA) e Barcarena (PA) e seu rebatimento no acesso e permanência a políticas educacionais; no segundo momento, são destacados os descaminhos da educação quilombola e as estratégias de resistência; por fim, as considerações acerca dos interesses do desmonte dos direitos à educação das comunidades quilombolas.

\section{Alteração dos limites sem consulta prévia e seus reflexos nas políticas públicas para a educação}

As populações tradicionais da Amazônia sofrem historicamente com o processo de negação de sua existência territorial. Quilombolas, ribeirinhos, agricultores familiares, pescadores, extrativistas, sitiantes são afetados por políticas públicas que desconsideram essas populações como produtoras e organizadoras de seus territórios. As políticas educacionais pensadas para essas populações nos município de Moju (PA) e Abaetetuba (PA) intensificam a reprodução das desigualdades dos lugares. Populações que necessitam de políticas específicas, como é o caso quilombola, não tem opção de escolha, uma vez que, como nos adverte Arruti (1999),

\footnotetext{
"O seu reconhecimento como um segmento diferenciado da sociedade nacional tende a se limitar à constatação de que mesmo entre os pobres e miseráveis do país há uma camada ainda mais desprivilegiada, excluída até mesmo das políticas públicas destinadas à atenuação da pobreza, do isolamento e da segregação" (ARRUTI, 1999, p. 83).
}

$\mathrm{O}$ autor aborda políticas públicas na esfera federal para quilombolas e ressalta o tipo de reconhecimento governamental dirigido a esses povos, notadamente o que reforça as desigualdades socioespaciais e étnico-raciais, entre as populações do campo e negras. Por isso, no âmbito federal, há políticas redistributivas, aquelas dirigidas à população em geral, políticas que desconsideram as especificidades dos povos quilombolas e que, nesse sentido, colaboram para o aprofundamento da pobreza (ARRUTI, 1999).

No âmbito das políticas educacionais no nível municipal, a prefeitura de Moju oferece o ensino fundamental completo. Abaetetuba oferece apenas o ensino fundamental menor ( $1^{\circ}$ ao $5^{\circ}$ ano), o maior (do $6^{\circ}$ ao $9^{\circ}$ ano) fica a cargo do governo do Estado. Na esfera 
estadual, a Secretaria de Estado de Educação (SEDUC) oferece o Sistema de Organização Modular de Ensino (SOME) para o ensino médio e o projeto Mundiar ${ }^{2}$ para o ensino fundamental.

Essa política pública educacional organizada pelas secretarias estadual e municipal é planejada sem nenhuma abordagem especial que contemple a realidade territorial dos povos que necessitam dessa perspectiva. Tais medidas do Estado dificultam a espacialização e territorialização das populações amazônidas. De acordo com Lefebvre (2016), o espaço

[...] é um meio nas mãos de 'alguém', individual ou coletivo, isto é, de um poder (por exemplo, um Estado), de uma classe dominante (a burguesia) ou de um grupo que tanto pode representar a sociedade global, quanto ter seus próprios objetivos, como os tecnocratas, por exemplo (LEFEBVRE, 2016, p. 44).

A concepção governamental nas referidas esferas gera políticas para as populações do campo sem a preocupação com as suas singularidades socioespaciais e étnico-raciais. As políticas públicas que apresentam esse formato se mostram insuficientes para atender às demandas dos lugares onde são implantadas. No domínio municipal, Abaetetuba, no seu Plano Municipal de Educação (PME) aprovado em junho de 2015, Art. $2^{\circ}$, chama a atenção as seguintes diretrizes:

$$
\begin{aligned}
& \text { X - promoção do respeito aos direitos humanos, à diversidade e à sustentabilidade } \\
& \text { socioambiental; } \\
& \text { XI - consideração das necessidades específicas das populações do campo e nas } \\
& \text { comunidades tradicionais: quilombolas e assentados de reforma agrária, } \\
& \text { asseguradas a equidade educacional e a diversidade cultural (ABAETETUBA, } \\
& \text { 2015, p. 1) (grifo meu). }
\end{aligned}
$$

O PME estabelece como diretiva considerar a singularidade, a diversidade das populações amazônidas. Todavia, o perfil das políticas indica preocupação com a população em geral apenas, contentando-se em oferecer precariamente serviços educacionais, desconsiderando a perspectiva de política efetivamente diferenciada no campo, como se verá

\footnotetext{
2 "O Projeto Mundiar é desenvolvido pela Secretaria de Estado de Educação (SEDUC) em parceria com a Fundação Roberto Marinho. O objetivo é acelerar a aprendizagem e corrigir o fluxo escolar dos estudantes em distorção idade/ano, possibilitando que eles terminem o ensino fundamental em 24 meses e o médio em 18 meses. A metodologia utilizada é da Telessala (videoaulas), uma proposta pedagógica voltada para a formação da cidadania e desenvolvimento de competências e para o mundo do trabalho. Os professores se dedicam exclusivamente a uma única turma. Eles ministram aulas em todas as disciplinas, em módulos, em que 15 minutos diários são de videoaulas, seguidos de atividades em sala de aula". Disponível em: http://www.seduc.pa.gov.br/site/seduc/modal?=5311. Acesso em: 12 set. 2017
} 
mais adiante quando confrontar o que consta nos documentos, nos dados das entrevistas de campo e nas observações diretas sobre a eficácia dessas políticas.

A prefeitura de Moju não disponibilizou na sua página na internet o Plano Municipal de Educação contendo diretrizes, objetivos e metas específicas para as populações tradicionais, tal como fez Abaetetuba, por isso não foi possível acessar o documento e verificar se há preocupação em atende as especificidades educacionais dos estudantes quilombolas ${ }^{3}$.

O governo do Estado, por meio da lei $\mathrm{n}^{\circ}$ 7.806, de 29 de abril de 2014, regulamentou o funcionamento do Sistema de Organização Modular de Ensino (SOME) como política pública do Estado. O Art. $2^{\circ}$ da referida lei, estabelece que,

“O Ensino Modular visa garantir aos alunos acesso à educação básica e isonomia nos direitos, assegurando a ampliação do nível de escolaridade e a permanência dos alunos em suas comunidades, observando as peculiaridades e diversidades encontradas no campo, águas, florestas e aldeias do Estado do Pará” (PARÁ, 2014). (grifo meu).

Ao abordarmos essa formulação contida na legislação, notamos preocupação com a diversidade, porém na execução da política não parece haver um esforço oficial para transformar a educação em um lócus da diversidade e da inclusão de povos do campo, das águas, das aldeias, da floresta como veremos mais adiante. O Art. 4 dessa mesma lei ressalta em três incisos os seguintes objetivos,

II - levar em consideração a diversidade territorial, reconhecendo os diversos povos do campo, das águas, das florestas e das aldeias, a fim da compreensão da dinâmica sócio espacial da Amazônia;

III - valorizar atividades curriculares e pedagógicas voltadas para o desenvolvimento sustentável, baseando-se na economia solidária e na inclusão dos povos que vivem no campo;

IV - garantir a manutenção dos laços de convívio familiar e comunitários dos jovens e adultos que, por necessidade de acesso e/ou continuidade dos estudos, teriam que se afastar dos costumes e valores de suas comunidades. (grifo nosso)

A elaboração da legislação novamente perpassa pelo tema da diversidade territorial, cultural das populações existentes no espaço agrário Amazônico. Na execução dessas políticas, as populações amazônidas enfrentam enormes dificuldades, tanto em obter

\footnotetext{
${ }^{3}$ Disponibilizou apenas a lei $n^{\circ} 844 / 2010$ que aprova o plano. Ainda assim, a análise será feita com os dados de campo, as observações diretas e a análise da eficiência das políticas.
} 
serviços públicos de qualidade, quanto ao acesso à educação social e culturalmente diferenciada, apontando como um de seus maiores problemas a ausência de uma educação voltada para as demandas dos povos quilombolas.

O "Projeto Mundiar" é parte integrante do "Pacto pela Educação" e entrou na política pública educacional do Estado em 2014 com o propósito de reduzir a distorção sérieidade para alunos do ensino fundamental maior a partir dos 13 anos e do ensino médio a partir dos 17 anos para que concluam o ensino fundamental em dois anos e o ensino médio em um ano e meio. Utiliza a metodologia telessala (uso de TV, vídeo) e unidocência, (um único professor ministrando aula de diferentes disciplinas), sendo diferente do ensino regular.

Para as populações do espaço agrário amazônico, as experiências educativas a partir dessa proposição têm se revelado traumáticas. Percebeu-se que embora a pretensão seja corrigir a distorção série-idade, os referencias metodológicos que fundamentam essas práticas são inadequados para a aquisição de conhecimento estratégico para um movimento de resistência. A realidade de inclusão precária e de exclusão põe as populações do campo em situação de desvantagem, atraso educacional.

A concentração de diferentes séries e conteúdos em um tempo menor para a realidade do campo não ajuda a construir uma educação que considere suas singularidades socioespaciais e étnico-raciais, conforme nos sugere Lefebvre (2016, p. 44), [...] um tal espaço se povoa segundo os decretos do poder, com um certo arbítrio; enquanto instrumento, ele pode reagir sobre os povoamentos preexistentes, a saber, os povoamentos históricos.

Em 10 de abril de 2008, o Instituto Brasileiro de Geografia e Estatística (IBGE) enviou ofício $N^{o}$ 108/08 respondendo à solicitação da Presidente do Tribunal Regional Eleitoral informando que as comunidades de Urubuputaua, Pau da Isca, Camorituba-Beira, Camorituba-Centro estão localizadas no município Abaetetuba (PA) e Camorituba-Baixo têm parte em Moju (PA) e parte em Abaetetuba (IBGE, 2008).

Verificou-se a partir dessa postura, como aponta Lefebvre (2016, p. 45), que "enquanto mediação, um tal espaço instrumental permite tanto impor uma certa coesão (pela violência), quanto dissimular as contradições da realidade (sob uma aparente coerência racional e objetiva)". Os órgãos governamentais agem desconsiderando a existência dos grupos que vivem nos seus lugares, interferindo nas formas de organização dos seus espaços, definido a priori o município à que devem pertencer, o que configura um tipo de violência ao direito dessas populações serem consultadas. 
Os grupos que compõem a porção do espaço entre os três municípios possuem identidades construídas no âmbito individual e coletivo ao longo de sua trajetória de existência no espaço, por meio do trabalho com a terra, da vivência no ambiente escolar, da convivência familiar, permitindo por meio dessa sociabilidade a construção de identidades territoriais (HAESBAERT, 1999) na tríplice fronteira municipal.

Com base nas informações enviadas pelo ofício do IBGE, a presidente do Tribunal Eleitoral transferiu todas as seções eleitorais localizadas nas referidas comunidades para Abaetetuba (IBGE, 2008) sem consulta prévia e sem considerar as identidades territoriais das comunidades afetadas. Bauman (2005, p. 46) salienta que nessas guerras pelo reconhecimento individual ou coletivo, o direito de adotar identidade de sua escolha é negado e "você é excluído do espaço social em que as identidades são buscadas, escolhidas, construídas, avaliadas, confirmadas ou refutadas".

Para agravar ainda mais as condições de existência do lugar, os limites entre dos três municípios já haviam sido modificados de acordo com o ofício № 108/08 (IBGE, 2008), interferindo no espaço de vida das comunidades, isto é, no território (FERNANDES, 2006), no qual vivem 18 comunidades $^{4}$ que constroem suas identidades territoriais (HAESBAERT, 1999). Nesse caso, a interferência no território se deu pela transferência das zonas eleitorais de Moju para Abaetetuba - sem falar nas escolas, postos de saúde, ramais, igrejas, barracões de festas, igarapés e outros - obrigando o mojuense a assumir a identidade de abaetetubense, modificando a base concreta que as comunidades usam como referência espacial simbólica para realizar suas relações.

As elites políticas locais - vereadores de Moju e Abaetetuba - estabelecidas nesses espaços receberam um convite da Assembleia Legislativa do Pará por meio do Memorando $\mathrm{N}^{\mathrm{o}}$ 173/2011 para uma reunião em Belém (PA), cuja pauta era discutir os limites dos referidos municípios (ASSEMBLEIA LEGISLATIVA DO PARÁ, 2011). Ainda assim, a política fragmentária do território segue ignorando as referências espaciais que servem de fundamente às identidades territoriais das populações tradicionais, como bem aponta Haesbaert (1999, p. 172), "não há território sem algum tipo de identificação e valorização simbólica (positiva ou negativa) do espaço pelos seus habitantes".

\footnotetext{
${ }^{4}$ As comunidades afetadas foram as seguintes: Caeté, África, Laranjituba, Guajaraúna, Divino Espírito Santo, Espanha, Maringá, Aguapé, São José, Cabresto, Camorituba Centro, Camurituba Beira, Anapu, Urubuputaua, Cupuaçu, Santa Cruz, Nossa Senhora do Carmo e Santa Cecilia.
} 
Em 28/01/2007, a Divisão Administrativa e Assuntos Municipais da Assembleia Legislativa do Pará recebeu de sua própria presidente uma solicitação de abertura do processo 000775/2007 5 para dar início a um plebiscito e permitir que as comunidades envolvidas decidam sobre o seu pertencimento (ASSEMBLEIA LEGISLATIVA DO PARÁ, 2007). Enquanto isso não acontece, as memórias coletivas e o imaginário das comunidades construídos a partir do território que compreende a tríplice fronteira municipal seguem confrontados pelas forças políticas dos poderes estatais, forçando-as a assumir outra identidade.

Ao acessar políticas públicas de educação, saúde, infraestrutura, assistência social e outras no seu conjunto, as referidas comunidades se depararam com a transferência permanente de responsabilidade, sendo que hora os serviços são exclusivamente de competência de Moju, hora de Abaetetuba. Ignoram o fato de que "as relações sociais e os territórios devem ser analisados em suas completividades. Neste sentido, os territórios são espaços geográficos e políticos, onde os sujeitos sociais executam seus projetos de vida para o desenvolvimento" (FERNANDES, 2006, p. 29).

A fragmentação territorial das comunidades inviabilizou a funcionalização das formas espaciais, isto é, escolas foram fechadas, a manutenção dos ramais foi suspensa, o serviço de transporte escolar deixou de ser prestado, famílias tiveram o benefício do Programa Bolsa Família suspenso por falta de orientação. Diante disso, a

"análise separada das relações sociais e dos territórios é uma forma de construir dicotomias. E também é uma forma de dominação, porque na dicotomia as relações sociais aparecem como totalidade e o território apenas como elemento secundário, como palco onde as relações sociais se realizam" (FERNANDES, 2006, p. 29).

Esse movimento de impasse na redefinição de limites entre os municípios expressa a relevância de processos políticos de fragmentação e fragilização territorial das populações amazônidas. Sob essa constatação, nos alerta Lefebvre (2016, p.45),

\footnotetext{
"Um tal espaço é ao mesmo tempo ideológico (porque político) e saber (pois comporta representações elaboradas). Pode-se, por conseguinte, denomina-lo racional-funcional, sem que tais termos possam separa-se, e funcional-instrumental, pois a função, no quadro global da sociedade neocapitalista, implica o projeto, a estratégia" (LEFEBVRE, 2016, p. 45).
}

\footnotetext{
${ }^{5}$ Trata-se de pedido formal de abertura de processo que ainda está em andamento. O Memorando No 173/2011 convidando vereadores dos municípios para a reunião sobre o problema da indefinição dos limites exemplifica que é preciso discutir o tema para que o processo seja aceito pela poder legislativo.
} 
Essa política fragmentadora do espaço acentuou as disputas por poder e influência entre os municípios e possibilitou emergir, procurado buscar formas organizadas de mobilização, as populações amazônicas em sua luta permanente pelo uso dos seus territórios por meio de movimentos reivindicatórios ou de resistência contrários a sua fragilização de suas identidades territoriais. Nesse aspecto, Cruz (2014) ressalta a década de 1980 como o momento em que os movimentos sociais se intensificam,

\begin{abstract}
“A partir de então, começa a esboçar-se na Amazônia uma nova 'geografia' que aponta para um processo de emergência de diversos movimentos sociais (índios, ribeirinhos, pequenos agricultores, seringueiros, varzeiros, castanheiros, populações quilombolas, mulheres quebradeiras de coco, etc.), que lutam pela afirmação de territorialidades e identidades territoriais como elemento de '(r) existência' das 'comunidades tradicionais'. Trata-se de movimentos sociais de "(r)existência", pois não só lutam para resistir contra os que exploram, dominam e estigmatizam essas populações, mas também por uma determinada forma de "existência", por um determinado modo de vida, por diferenciados modos de sentir, agir e pensar" (CRUZ, 2014, p. 51-52).
\end{abstract}

Foi no âmbito das políticas públicas educacionais que os efeitos dessa prática fragmentadora do território ganharam contornos geográficos mais graves. Ela foi citada com frequência pelas populações atingidas pelas disputas entre os municípios limítrofes. Os representantes das comunidades atingidas procuraram a Defensoria Pública do Estado do Pará do Núcleo de Direitos Humanos e Demandas Estratégicas no dia 04 de maio de 2017 e se reuniram com o Defensor Público, cujo assunto dizia respeito à intervenção para garantias de direitos educacionais (DEFENSORIA PÚBLICA DO ESTADO DO PARÁ, 2017).

A marginalização educacional vivida pelas comunidades rurais engendrou reações que os levou a acionar as instituições governamentais para atender a sua realidade, desse modo, "a constituição desses novos sujeitos dá-se nas e pelas lutas de afirmação de suas identidades culturais e políticas pautadas na territorialidade, logo, são lutas pela afirmação de suas identidades territoriais" (CRUZ, 2014, p. 55).

A partir daí, a defensoria pública atendeu a solicitação dos representantes e marcou uma reunião somente com as comunidades afetadas no quilombo de África e Laranjituba, dia 12 de junho de 2017 para "ouvir previamente a população local, bem como entender e colher documentos acerca da situação" (DEFENSORIA PÚBLICA DO ESTADO DO PARÁ, 2017, p. 2).

Embora a reunião tenha sido convocada somente para ouvir as comunidades, compareceram, entre outros, quatro vereadores do Moju e um deputado estadual. Significa dizer 
que chamou a atenção da instância legislativa do poder público municipal frente à mobilização das comunidades amazônicas. Para Cruz (2014, p. 53), "trata-se de um processo de ressignificação política e cultural que esses grupos sociais vêm fazendo de sua experiência cultural e da sua forma de organização política”. Já Fernandes (2005, p 31), num esforço e desafio de ir além do sociológico, categoriza esses agentes como "movimentos socioterritoriais", isto é, aqueles que "têm o território não só como trunfo, mas este é essencial para sua existência”.

O desafio das comunidades atingidas pela redefinição das fronteiras entre Moju, Abaetetuba e Barcarena no estado do Pará é garantir o reconhecimento dos seus direitos, sobretudo educação específica e de qualidade. Todavia, o que prevaleceu foi uma partilha territorial das populações movida por interesses políticos locais articulados com interesses em escala global sem preocupação com as especificidades territoriais desses povos. Os efeitos do jogo político entre os municípios agravou a situação geográfica do lugar, conforme relato da entrevistada 1, professorada comunidade Camorituba Beira,

\begin{abstract}
"Sou formada pela UFPA e hoje na situação que a gente tá colocando são algumas questões da Escola São Luiz (...) então, a Escola São Luiz funcionava do ensino infantil ao $9^{\circ}$ ano já com uma expectativa de ensino médio para este ano, já tinha demanda para o ensino médio, sou a tesoureira do conselho escolar da Escola São Luiz também e que se encontra parado no conselho escolar até definirem essa situação em que a gente se encontra. Então, a Escola São Luiz tinha 13 funcionários efetivos que trabalhavam no município de Moju e que fomos todos remanejados(...) Mas a grande preocupação da escola hoje enquanto professora é a questão dos meus alunos que eu deixei prontos pra irem para o $6^{\circ}$ ano, que até final do ano nós fizemos uma feira de ciência e cultural, os meus alunos trabalharem identidade. O tema da nossa feira de ciência foi histórias e vivências da comunidade do Camorituba Beira. Então, a gente trabalhou um bimestre todinho, todos os professores se dedicando na identidade daquele aluno dizendo que ele era de Moju, que ele tem alguns familiares são daqui da África e são descendentes quilombolas, são do Aguapé, são lá da beira do rio, são ribeirinhos, então a gente passou uma eternidade ensinando pra aquela criança que ela era mojuense, que a identidade dele é ribeirinha, é um pouco quilombola e toda uma descendência dele, e agora? $\mathrm{O}$ meu aluno terminou dezembro mojuense, aprendendo tudo sobre Moju. Começa o ano letivo de 2017 e o meu aluno precisa esquecer tudo aquilo que eu ensinei pra ele, pra ele aprender que ele é de Abaetetuba. Olha a cabecinha do aluno do $5^{\circ}$ ano e do $3^{\circ}$ ano que era as minhas duas séries. Como é que fica?" (Entrevista realizada em 12de junho de 2017).
\end{abstract}

O descontentamento com os resultados dessa ação governamental envolvendo conflitos de poder e rivalidade por hegemonia expressos no relato é revelador e se destina às práticas que ignoram as identidades territoriais que, segundo Haesbaert (1999, p.178), "tratase de uma identidade em que um dos aspectos fundamentais para a sua estruturação está na 
alusão ou referência a um território, tanto no sentido simbólico quanto concreto". Tal postura nega o acesso à educação, à informação e à participação nos processos decisórios. Trata-se de uma estratégia de fragmentar e enfraquecer qualquer possibilidade de mobilização e reação das populações prejudicadas. O processo de desmonte das conquistas pelo direito à educação é relatado pelo entrevistado 2 de Maringá,

"Eu só quero um consenso para o povo olhar e se tem algum erro com a nossa educação, daqui para frente, bora vê se nós ajeita isso para o futuro de nossos filhos e que nosso filho tenham uma oportunidade de ter um ensino mais adequado. Eu vou dizer uma coisa para vocês, eu sou mojuense, o meu título tá aqui no bolso, ainda dá voto para o Moju. Eu transferi, quando foi, eu dormi e acordei Abaetetuba, aí transferi meu título pra Abaetetuba [...] Moju tá tendo hoje só os alunos e mais nada. Toda a mossa produção é escoada para Abaetetuba, e foi transferida a educação para Abaetetuba, mas só de palavra. Nós não tivemos uma reunião com as secretarias, pelo menos ou com os coordenador que coordenava lá o Alberto Gomes para falar que tava com Abaetetuba e quando terminou a escola parou. Nós fiquemo mais de um mês parado e aí nós fomu percurá providência, corremo pra Abaetetuba e aí não podiam arcar e aí teve o MUNDIAL que nós tomemo lá, que muitos já falaram e não é bão, mas foi quem nos aparou lá, pro nossos filhos tá estudando, mais de 80 alunos, e o colégio lá parado e fechado, e aí fumo, como o colégio tava fechado e não deram a chave pros meninos estudá la dentro [...]" (Entrevista realizada em 12 de junho de 2017).

Nota-se que o relato ressalta a urgência na tomada de medidas que tenham conteúdo fortemente baseado no reconhecimento dessas comunidades, inserindo na agenda pública demandas ignoradas e ainda ampliando as possibilidades de participação no processo de tomada de decisão. É por isso que "as relações não se desenvolvem no vácuo, mas sim nos territórios. As relações são construídas para transformar os territórios" (FERNANDES, 2006, p. 29).

A esse respeito, vale ressaltar que a dificuldade de diálogo entre a organização das comunidades atingidas e as instâncias governamentais compromete seriamente as políticas públicas em favor da melhoria das condições de existência dos lugares. $\mathrm{O}$ entrevistado 3 da comunidade de Aguapé destaca esse avanço conservador sobre as escolas,

"Sou da comunidade do Aguapé, o objetivo nosso aqui é sobre as escolas. Quando Moju fez o repasse e que nós não pertencia mais a Moju, ele não comunicou ninguém, ele nos largou abandonado, as escolas ficou abandonada, a comunidade ficou abandonada e não teve valor e se respeitasse meno um pouco de dignidade teria comunicado a comunidade. Aí o que nós fizemos, nós reunimos a comunidade, fomo até Abaetetuba, conversemo com Abaetetuba, a secretaria veio até a comunidade, ela tá até aí, reunimo lá. Abaeté abraçou a comunidade, a gente já é Abaete mesmo, gente só é título que é Moju. Aí nós lotemo as pessoa, ela lotô lá com a gente, coloquemo funcionário pra trabalhar, começaram em março, trabalharam três meses, a escola lá é Santa Bárbara, três meses e agora recebemos 
uma notícia que era pra parar, tem um professor ali e foi parada a aula e as crianças ficaram sem aula, na terça-feira, há oito dias atrás". (Entrevista realizada em 12 de junho de 2017).

Entretanto, ao refletir sobre o contexto atual da região amazônica, a redefinição dos limites entre os três municípios citados, quanto às políticas públicas para a educação, que dão sustentação à existência territorial das comunidades, ignorou o direito de afirmação identitária nos territórios onde se encontram. No entanto, compartilhando com os argumentos de Bauman (2005, p. 84), "a identidade é uma luta simultânea conta a dissolução e a fragmentação; uma intensão de devorar e ao mesmo tempo uma recusa resoluta a ser devorado (...)".

Tal situação se agrava com a redefinição dos limites sem consulta prévia, livre e orientada. Essa postura governamental violou o artigo $6^{\circ}$ da Convenção $n^{\circ} 169$ sobre povos indígenas e tribais, da qual o governo brasileiro é signatário. Tal artigo estabelece que,

a) consultar os povos interessados, por meio de procedimentos adequados e, em particular, de suas instituições representativas, sempre que sejam previstas medidas legislativas ou administrativas suscetíveis de afetá-los diretamente;

b) criar meios pelos quais esses povos possam participar livremente, ou pelo menos na mesma medida assegurada aos demais cidadãos, em todos os níveis decisórios de instituições eletivas ou órgãos administrativos responsáveis por políticas e programas que lhes afetem; (NAÇÕES UNIDAS, 2011).

Tal postura institucional restritiva de direitos territoriais causou sérios problemas à existência dessas populações. Sobre os problemas vivenciados pela Comunidade Anapu, o entrevistado 4 destaca,

"Quero dizer o seguinte, o estrago ele é muito maior do que tá se falando. Parece
que o problema territorial, da mexida territorial foi só na educação e não foi, tá. Nós
temos outros problemas, problemas sociais que por essa disputa de poder me parece,
que afeta quem não tem nada a ver com isso, tá. Nós somos uma população, somos
cidadãos de direito e nós temos direito de expressar nossa opinião, só que tem horas
parece que esses direitos não são respeitados [...] Eu, a escola Santa Ana Cristina, é
uma escola que eu ajudei a construir. Em 1999, quando começou a construir a
escola, eu meus irmãos, meus primos íamos pra pedreira carregar pedra pra construir
aquela escola, porque nós tínhamos uma escola que estava caindo construída de
madeira e, hoje, nós temos um prédio abandonado, o prédio lá tá abandonado e nós
temos sim na comunidade Anapu, Pau da Isca, a comunidade da Vila Bufete que
também é beneficiada da ali da comunidade Anapu da escola Santa Ana Cristina.
Alunos da Colônia Nova que estudaram na Santa Ana Cristina, alunos do
Camorituba que estudaram na escola Santa Ana Cristina que não estão estudando, tá,
nós tínhamos lá quase 200 alunos, que era da infantil ao Sistema Modular do ensino 
médio, só que não foi fácil conseguir isso pra lá e hoje nós vivemos uma estrutura abandonada, tá, então, eu gostaria de saber, como é que se decide isso? Parece que foi tão fácil pra tirarem isso da gente, né, eu não sei quantas pessoas se reuniram pra tirar isso da gente, e nós já fizemos, eu acho, desde 2008, 2010 que a gente vem lutando. Primeiro passaram os títulos sem consultar ninguém, tá, sem nenhuma consulta prévia, o pessoal já tá falando isso aqui eu já nem queria repetir, mas primeiro passaram os títulos eleitorais de todo o mundo pra Abaetetuba como se ninguém pudesse dar sua opinião, como se nós fôssemos aqueles que tivessem sido guiados pelos outros e ninguém pudesse dar sua opinião, o primeiro problema começa bem aqui [...]" (Entrevista realizada em 12 de junho de 2017).

O morador da comunidade expressa sua indignação em virtude da ausência de escolas com possibilidade de estudo para as crianças e a oportunidade em deliberar sobre qualquer decisão que interfira na existência dos grupos. Observamos, pelo discurso do entrevistado, que educação é o direito fundamental violado que mais se destaca. As identidades territoriais dos sujeitos envolvidos nessa luta contra a subtração de seus direitos reivindicam critérios de reconhecimento específicos para a inserção territorial na cidadania. Martins (1993), analisando os processos gerados pela figura do estranho na Amazônia, e nesse caso o estranho aqui é o funcionário governamental, ressalta que,

\footnotetext{
"Não se trata de introduzir nada na vida dessas populações, mas de tirar-lhe o que tem de vital para sua sobrevivência, não só econômica: terra e territórios, meios e condições de existência material, social, cultural e política. É como se elas não existissem ou, existindo, não tivessem direito ao reconhecimento de sua humanidade" (MARTINS, p. 63).
}

Outra preocupação que aflige as comunidades e pode ser percebida no relato do entrevistado 5 da comunidade de Moju-miri, é com o projeto de ligação ferroviária Açailândia (MA)-Barcarena (PA),

\footnotetext{
“Agora a situação é que a professora sempre fala pra nós, que é só uma professora pra 30 e poucas crianças, criancinha, tem criança já da $1^{\mathrm{a}}$ série, da $2^{\mathrm{a}}$ série, aí meus amados acarreta lá a professora, e aí ela fica meia agoniada, você sabe como é as crianças de hoje. Então a gente queria que vocês olhassem com carinho pra gente lá sobre essa questão do ramal, da linha aí da divisão de municípios que a gente não sabe, a gente só ouve falar por informação, e aí a gente queria que esclarecesse isso melhor que era pra gente, com diz aqui os companheiros que já falaram, correr atrás do pai da criança, saber que é que vai assumir de fato e de direito. E outra coisa meus amados, eu quero pedir a vocês que são autoridades, a gente tá ouvindo falar, viu deputado, ouvindo falar dessa ferrovia que vem e aí a gente tá meio desinformado, e o nosso amigo aqui, isso não é questão pra esse assunto, não sei, mas eu como presidente de associação e vocês como autoridade deve aproveitar oportunidade que é rara as vez né, então quando tá aqui os deputados, os vereadores
} 
que tão no nosso meio fica mais fácil da gente falar e aí a gente queria provocar com vocês políticas pública pra vocês esclarecerem pra nós, porque, às vezes, a gente já tá desinformado e aí vê quando já vem chegando o negócio e aí não tem até como a gente se prevenir, então a gente queria que vocês se preocupassem em informar pra nós como é que tá acontecendo isso [...]" (Entrevista realizada em 12 de junho de $2017)^{6}$.

Estas ações governamentais requerem uma leitura articulada e contextualizada, porque a negação de políticas públicas voltadas para a saúde, o transporte, a assistência social e, sobretudo, a educação interessam a setores conservadores representados por mineradoras, pelo agronegócio e outros que serão beneficiados com a exploração da ferrovia. Isso nos dá elementos para supor que a fragilização dos territórios das comunidades amazônidas, seja pela redefinição de limites, seja pelo desmonte das conquistas mínimas na educação, sem nenhuma informação ou consulta prévia, dialoga com o referido projeto de logística ferroviária pensado para Amazônia.

Trata-se do Plano de Investimento em logística (PIL) lançado em 15 agosto de 2012 pelo Governo Federal e que compreende um conjunto de projetos para ampliar o sistema de transportes rodoviário, ferroviário, hidroviário e aeroviária no país (BRASIL, 2014). Em 09 de junho de 2015, o Governo Federal anunciou a segunda etapa do programa, o PILFerrovias, incluindo o trecho da Ferrovia Norte-Sul ligando Açailândia (MA) até o porto de Vila do Conde em Barcarena (PA) (BRASIL, 2014).

\section{Descaminhos da educação e resistência no território quilombola}

Surpreendidos pela alteração dos limites municipais, ocasionando transferência, indefinição de responsabilidades e fechamento de escolas, as lideranças do quilombo de África e Laranjituba denunciaram o problema à Defensoria Pública. O apelo dos quilombolas levou a uma grande mobilização de diferentes comunidades, levando a Defensoria Pública a solicitar uma reunião com as comunidades para ter uma real dimensão dos impactos, avaliálos e mensurá-los.

Em 02 de maio de 2017, a Defensoria Pública do Estado do Pará - Núcleo de Defesa dos Direitos Humanos e Ações Estratégicas (NDDH), solicitou no prazo de dez dias, a listagem das escolas municipais e estaduais das comunidades atingidas, os meios de

\footnotetext{
${ }^{6}$ Durante a entrevista, o sujeito entrevistado 5 percebeu a presença de vereadores e passou a proferir um discurso que pudesse chamar a atenção deles. Percebendo isso, optou-se por deixa-lo à vontade para expressar sua indignação e valorizar sua fala.
} 
transporte escolar que as servem, a data que Abaetetuba assumiu as escolas, os documentos das escolas assumidas junto como repasse de verbas e situação das unidades escolares, atos normativos de transferência das escolas, do funcionamento dos conselhos escolares, atos de repasse do Fundo Nacional de Desenvolvimento para a prefeitura de Abaetetuba, a lista das escolas contempladas pelo fundo e seus respectivos valores (BELÉM, 2017)

Segundo a Defensoria Pública, as informações solicitadas não foram enviadas, mesmo sendo estipulado prazo de dez dias,

'[...] O nosso procedimento está em consonância com todo mundo, a gente tá tentando dialogar com todo mundo. Porém, desde quando o processo começou e eu tenho todas as atas das reuniões realizadas com a comunidade, com as pessoas, com a secretária, inclusive eu falei com a secretária situações de violações de direitos que geraria uma responsabilidade dos municípios e aí houve essa reunião e aí a gente foi pego de surpresa e a comunidade também. A secretária de educação de Abaetetuba já recebeu duas requisições de informações sobre os procedimentos que Abaetetuba vem tomando desde janeiro até agora. Ela já recebeu isso e seque respondeu, eu vou de novo cobrar as informações [...]" (Entrevista realizada em 12 de junho de 2017).

No mesmo dia ocorreu uma reunião na Promotoria de Justiça de Abaetetuba para tratar da transferência de escolas localizadas nos limites dos municípios de Moju e Abaetetuba. Estavam presentes, além dos promotores de justiça de Abaetetuba e de Moju, a $3^{\mathrm{a}}$ Unidade Regional de Educação - $3^{\mathrm{a}}$ URE Secretaria Municipal de Educação de Abaetetuba, a Secretaria Municipal de Educação de Moju, o Conselho Municipal de Educação,o Fórum Municipal de Educação de Abaetetuba, o Conselho Tutelar Rural de Abaetetuba, a Câmara Municipal de Abaetetuba, a Câmara Municipal de Moju e o representante de pais de alunos da comunidade Vila Aguapé (PROMOTORIA DE JUSTIÇA DE ABAETETUBA, 2017).

A prefeitura de Abaetetuba assumiu nove escolas do Moju sem ter nada formal que legalizasse tal transferência como ato administrativo, caracterizando transferência informal das escolas e sem consulta prévia as comunidades envolvidas. A decisão dos promotores indica Moju com o dever de manter a oferta de serviços de educação para as comunidades e determina o retorno imediato dos serviços da educação e ainda realizar a transferência de forma legal consultando todos os interessados (PROMOTORIA DE JUSTIÇA DE ABAETETUBA, 2017).

Ainda assim, as aulas do ensino fundamental maior (do $6^{\circ}$ ao $9^{\circ}$ ano) não voltaram ao normal na Escola Municipal Bento Lima de Oliveira localizada na comunidade de África e Laranjituba depois de mais de quatro meses, desde 30 de novembro de 2016. A Escola 
Municipal Baixo Caeté onde funciona o ensino fundamental menor (do $1^{\circ}$ ao $5^{\circ}$ ano), também enfrenta sérios problemas, conforme afirma a entrevistada 6 mãe de aluno da comunidade de Laranjituba:

“[...] A outra escola é a Laranjituba que é a escola do Baixo Caeté que inclusive agora não se chama mais Baixo Caeté, mas vai se chamar Militão, devido já funcionar por Abaetetuba, porque ela já funciona o ensino fundamental menor e aí já foi contratado um sobrinho meu professor praí pra lá, mas não sabe até quando porque na última reunião, ele disse que talvez não seja mais o professor esse mês que vem, porque a prefeitura ainda não pagou porque querem só pessoas que sejam concursadas, o prefeito tem que mandar pessoas concursadas, então a gente não sabe como é que vai ficar a nossa situação das nossas crianças. E é mais ou menos esse o nosso problema e aí a gente tá lutando pra que a gente consiga levar a nossa escola adiante. A escola está em condições precárias, fomos abandonados tanto por Moju quanto por Abaetetuba, não temos nenhum acompanhamento da prefeitura, nenhuma das duas. A prefeitura bancava professores, ou banca professores e nós não temos uma servente, nós não temos uma faxineira, nós não temos ninguém, só as pessoas da comunidade que se põem como voluntários" (Entrevista realizada em 12 de junho de 2017).

Os interesses políticos que conduzem o movimento de redefinição dos limites entre os dois municípios impedem o funcionamento das escolas, afetando sobremaneira a identidade territorial das comunidades. Os interesses por tal alteração deixam as escolas em situação ainda mais precária, conforme afirma a aluna da escola, entrevistada 7 ,

"A escola Bento Lima está sem aula mais de quatro meses, desde 30 de novembro de 2016. De manhã era o fundamental maior, mas quando passaram pra Abaetetuba ficou assim mesmo, sem aula. O ensino médio é a tarde pelo SOME, das 3 da tarde até seis. É um horário que a comunidade escolheu porque muita gente trabalha de manhã e não dá pra vim andando no sol quente e não tem transporte para vim a noite. Tinha transporte a noite, mas com o novo prefeito isso foi cortado, foi mais por questão política mesmo, ele aqui na comunidade não conseguiu o voto e aí mano, já viu. Existe carência de professores na disciplina sociologia, de pessoal administrativo, diretor e vice-diretor, pedagogo, coordenador... Falta recurso pedagógico. Os livros que temos aqui são doações. Agora que veio um professor de sociologia que precisa repor as aulas e não sei como ele vai fazer isso. Eles vão resumir o máximo e ainda tem o pessoal do ano passado que precisam de reposição de aula, e aí o Magno mandou o ofício para a SEDUC pedindo os professores pra repor essas aulas. Aí a coordenadora já surgiu uma lei não sei das quantas dela lá que não é preciso, que os alunos não vão ficar prejudicados e vão receber mesmo assim o certificado, mas como se a pessoa não vai estudar aquela matéria, e aí? Tudo isso vai desmotivando a gente". (Entrevista realizada em maio de 2017).

As tentativas de acesso à educação esbarraram nas disputas político-partidárias municipais, tornado ainda mais difícil o reconhecimento dos direitos do território quilombola. 
As disputas acima citadas negam o direito dos quilombolas à educação em geral e uma educação diferenciada como política pública afirmativa. Diante dessa situação, são necessárias propostas condizentes com a educação quilombola e, imaginar o espaço agrário sob outra perspectiva, isto é, "pensar o campo como território significa compreendê-lo como espaço de vida, ou como um tipo de espaço geográfico onde se realizam todas as dimensões da existência humana" (FERNANDES, 2006, p. 28-29).

Nesse contexto, tais reivindicações territoriais devem ser entendidas como legalmente instituídas, relacionadas a direitos constitucionais específicos dos quilombolas, que não se resumem à educação, incluindo também a preservação de uma identidade, o direito à viabilidade da circulação nos ramais, o transporte escolar, o direito à consulta prévia, a políticas públicas diferenciadas para populações quilombolas, isto é, se dá no/pelo território. Na perspectiva de Fernandes (2006),

\footnotetext{
"Educação, cultura, produção, trabalho, infra-estrutura, organização política, mercado etc, são relações sociais constituintes das dimensões territoriais. São concomitantemente interativas e completivas. Elas não existem em separado. A educação não existe fora do território, assim como a cultura, a economia e todas as outras dimensões. A análise separada das relações sociais e dos territórios é uma forma de construir dicotomias. E também é uma forma de dominação, porque na dicotomia as relações sociais aparecem como totalidade e o território apenas como elemento secundário, como palco onde as relações sociais se realizam. Contudo, as relações não se desenvolvem no vácuo, mas sim nos territórios. As relações são construídas para transformar os territórios. Portanto, ambos possuem a mesma importância" (FERNANDES, 2006, p. 29).
}

África e Laranjituba em Moju (PA) constituem um dos dezoito territórios que sofrem com o desmonte da educação. O quilombo possui 193 habitantes, 82 em África e 111 em Laranjituba, distribuídos em 72 famílias numa área de 1108,18 ha. Quanto às condições de acesso à educação, duas escolas ajudam a compor a configuração espacial do lugar. A Escola Municipal de Ensino Fundamental Bento Lima de Oliveira em África e a Escola Municipal de Ensino Fundamental Baixo Caeté em Laranjituba. A primeira oferece o ensino médio modular em apenas um turno com professores lotados pelo Estado e o ensino fundamental do $6^{\circ}$ ao $9^{\circ}$ ano que não funciona, deixando os alunos negros à margem do direito à educação. O número elevado de falta dos professores ao longo do mês prejudica a regularidade das aulas no ensino médio.

A entrevistada 8, mãe de aluno da escola relata que, 
"A escola Bento Lima na comunidade África não tem aula desde 30 de novembro de 2016. Quinta-feira passada que teve três alunos num dia e no outro quatro e agora foi de novo quinta e sexta-feira que o professor veio. Eu disse a ele, olha professor vê se o senhor vem. Eu já tinha ligado pro Magno pra ele pedir outro professor que desse jeito pra mim não dá. E aí ele veio com essa desculpa dele foi lá no Moju e a Leia disse que não ia mandar mais professor praí, eu digo ela não vai, vai vê se ela não vai! Ela tá pensando que a gente tamo brincando, a gente já engoliu muito sapo, cobra, tudo mas agora a gente não engoli mais, agora agente vai pra cima. Eles não dão aula e ganham sete mil reais. É verdade, eles ganham sim. A professora foi lá no Moju e a Leia disse pra ela, o professor não tá indo dá aula, mas ele ganha sete mil todo mês, mas eu digo, ele não vai ganhar porque a gente vai marcar os dias que ele veio e os dias que ele não veio e aí, o dia que ele não veio manda descontar. Eu digo pros alunos, o dia que não tiver aula, vocês marcam lá que eu vou marcar no meu caderno, eu vou botá valendo com esses professores". (Entrevista realizada em 12 de junho de 2017).

Os processos educacionais não permitem a realização do reconhecimento de sua cultura, pois não há articulação entre conhecimento escolar e conhecimentos quilombolas. Freire (1996), ao enfatizar a importância de ensinar com respeito aos saberes do educando, sugere que

"por isso mesmo pensar certo coloca ao professor ou, mais amplamente à escola, o dever de não só respeitar os saberes com que os educandos, sobretudo os das classes populares, chegam a ela - saberes socialmente construídos na prática comunitária mas também, como há mais de vinte anos venho sugerindo, discutir com os alunos a razão de ser de alguns desses saberes em relação com o ensinos dos conteúdos" (FREIRE, 1996, p. 33).

\title{
A entrevistada 9, aluna concluinte do ensino médio, reforça essa perspectiva
}

\begin{abstract}
"Eu concluí o ensino médio, sou ex-aluna da escola Bento Lima. Já faz uns quatro meses, começa toda vez em março e ainda não começou o ensino fundamental. Tem professor dando aula, mas só ensino médio e começaram agora esses tempos. Agora tá tendo Sociologia e Geografia, é Sistema Modular, cada mês vem outras disciplinas, aí outro módulo. Até agora tá sem nada de funcionário, só a gente que vai pra lá limpar, os alunos que levam água. Até que livro tem bastante lá. Os professores, tem uns que vem e tem outros que faltam muito. Sobre sociologia a gente ficou sem essa reposição e aí a Arleia ligou e disse que iam cobrir com outras notas e um professor que disse que vinha, vinha e não veio, tem uns que são assim. As aulas não tem nada a ver com a comunidade, todas trazem assuntos lá de fora, agora esses aqui da comunidade ninguém trata" (Entrevista realizada em 12 de junho de 2017).
\end{abstract}

Constatamos que o quilombo necessita de diversas ações afirmativas que promovam um sistema de ensino voltado para crianças, jovens, adultos e idosos capaz de 
dialogar com as demandas territoriais desses povos e que façam referência à identidade territorial e às práticas socioespaciais desses grupos. Para Freire (1989),

“[...] as palavras com que organizam o programa da alfabetização deveriam vir do universo vocabular dos grupos populares, expressando a sua real linguagem, os seus anseios, as suas inquietações, as suas reivindicações, os seus sonhos" (FREIRE, 1989, p 13).

O gráfico a seguir revela dados preocupantes da falta de acesso à educação em África e Laranjituba. Trata-se de informações acerca do acesso e permanência, da realização de políticas públicas em um território quilombola. Observe o gráfico 1.

\section{Gráfico 1 - Escolaridade em África e Laranjituba (2016)}

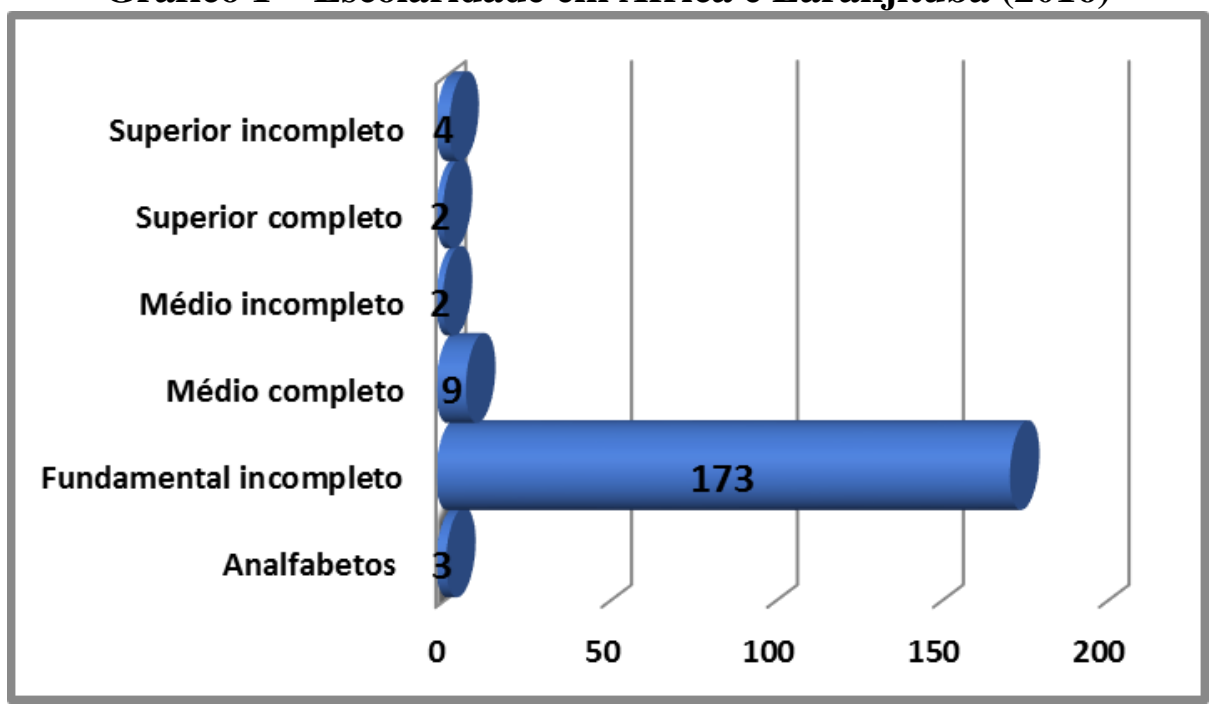

Fonte: Organizado pelos autores, Out/2016. Pesquisa de campo.

Notem que os dados demonstram fortes desigualdades acerca da realização educacional no lugar. Analisando a escolaridade, observamos que embora haja uma baixa taxa de analfabetismo, 3 pessoas (1\%), é elevada a taxa do nível fundamental incompleto, $90 \%$ do total, isto é, são 173 com baixíssima escolaridade. Isso nos permite afirmar que a forma de pensar o espaço nas políticas educacionais elimina a existência territorial quilombola. A noção abstrata do espaço impera nas políticas, isto é, “espaço é forma pura” (LEFEBVRE, 2016, p.41).

Ultrapassar as barreiras do ensino fundamental para médio e deste para o superior se torna muito difícil, pois os dados mostram que 5\% (9 moradores) e 1\% (2 moradores) respectivamente possuem ensino médio completo e incompleto. A taxa do nível superior completo representa $1 \%$ ( 2 moradores) e superior incompleto $2 \%$ (4 moradores). Mesmo com 
as políticas de cotas, acesso ao ensino superior, o ingresso e a permanência nos níveis fundamental e médio torna-se bastante precário, impedindo a progressão aos níveis educacionais mais elevados. Esses dados nos permitem afirmar que a política de educação para o quilombo considera o espaço como simples continente vazio de conteúdo social, de relações concretas. Nesta perspectiva,

\footnotetext{
"O espaço abstrato funciona 'objetalmente' como conjunto de coisas-signos, com suas relações formais: o vidro e a pedra, o cimento e o aço, os ângulos e as curvas, os plenos e os vazios. Esse espaço formal e quantificado nega as diferenças, as que provêm da natureza e do tempo (histórico), assim como as oriundas do corpo, idades, sexos, etnias" (LEFEBVRE, 2006, p.48).
}

Os dados nos ajudam a pensar aspectos definidores do processo de reprodução das desigualdades no lugar, uma vez que crianças e jovens matriculados no ensino básico regular terão, provavelmente, maiores oportunidades de formação superior. Com os alunos fora da escola e sem perspectiva de desenvolvimento de uma educação diferenciada quilombola (ARRUTI, 1999) muitos desistem de estudar, outros abandonam o território.

Significa dizer que a política educacional para quilombos concebe o espaço como puro e vazio, esquecendo as práticas sociais do lugar. Trata-se do espaço concebido pelos planejadores municipais e estaduais das políticas que promovem o esvaziamento das práticas espaciais quilombolas e ignoram a educação, “esta dimensão territorial é espaço essencial para o desenvolvimento de seus territórios" (FERNANDES, 2006, p. 30).

Preocupados em "pensar a educação quilombola com base nos contextos de uso do território, da etnicidade e da memória presentes nas narrativas dos sujeitos..." (CARRIL, 2017, p. 555), as lideranças fortaleceram as lutas pela identidade cultural nas escolas e combateram políticas territoriais de educação que desconsideram as suas especificidades acionando a defensoria pública para cobrar do Estado, da prefeitura e ainda convocaram reunião para discutir problemas que os afligem e para fazer valer a consulta prévia sobre qualquer mudança que afete o seu território. Por isso, "pensar o campo como território significa compreendê-lo como espaço de vida, ou como um tipo de espaço geográfico onde se realizam todas as dimensões da existência humana" (FERNANDES, 2006, p. 28-29).

O quilombo de África e Laranjituba, articulado a outras comunidades não quilombolas, à União de Negros pela Igualdade (UNEGRO), à Federação Quilombola do Estado do Pará, ao Centro de Estudos e Defesa do Negro no Pará (CEDEMPA) procura agora sua legitimação e reconhecimento via instituições públicas com a Defensoria Pública e o 
Ministério Público na luta por políticas educacionais específicas que atendam as necessidades do lugar. Daí pensar a educação como política pública basilar para os quilombolas, isto é, “esta dimensão territorial é espaço essencial para o desenvolvimento de seus territórios" (FERNANDES, 2006, p. 30).

Esse processo de desorganização e ruína da educação no quilombo em meio a disputas de limites entre os municípios nos ajuda a entender que a problemática não se reduz a uma simples disputa político-partidária. Esse discurso tem sido o argumento recorrente utilizado pelos agentes governamentais das instâncias do poder executivo e legislativo para expor o problema. Todavia, para entendermos o contexto das tensões hoje configurados nos municípios de Moju, Abaetetuba e Barcarena, é necessário visualizar que na região que compreende esses municípios estão instalados grandes projetos - ALBRAS/ALUNORTE, monocultura de dendê e outros - e ainda há projetos de logística ferroviária (AçailândiaBarcarena) que ameaçam os quilombolas.

Isso nos leva a crer que o território vai muito além do que hoje é demarcado como disputa entre dois ou mais municípios. Considerando o contexto atual da região, a redefinição dos limites corresponde a articulações de interesses a espaços em escalas que transcendem o local, o regional e alcançam o nacional e o global. É preciso entender que a região compreende produção e fluxo de commodities (dendê, madeira, alumínio, carne...). Os recursos naturais têm se constituído num elemento de disputa territorial e a fragilização da identidade e das condições de existência territorial, como é caso da educação, constitui instrumento de manipulação nessa contenda.

\section{CONSIDERAÇÕES FINAIS}

A insuficiência de políticas públicas em geral e educacionais em particular, assumiu uma dimensão geográfica muito grave a partir das disputas municipais de limites, o que colocou em risco a existência territorial de diferentes comunidades. De modo particular, representou o esquecimento das práticas e experiências territoriais e do espaço vivido impedindo a progressão a níveis educacionais mais elevados, daí as baixíssimas taxas de escolarização que fragilizaram a segurança territorial e confrontaram a identidade territorial das comunidades que buscaram na organização e politização de suas práticas o fortalecimento de suas identidades coletivas, imprimindo resistência à ofensiva governamental. 
As lideranças se posicionaram para romper com essa sofrida trajetória de negação dos seus direitos. Ocorre que, atualmente, a situação de assunção das responsabilidades pelas políticas públicas se mantém indefinida, o que caracteriza uma situação de insegurança, afetando as identidades territoriais. Verificou-se que as disputas que envolvem a alteração dos limites entre os municípios não é suficiente para compreender e explicar os problemas graves enfrentados pelas comunidades. Interesses de diferentes agentes em diferentes esferas devem ser considerados numa análise geográfica. Limitar a análise na escala local implica no risco de perder o movimento do todo.

\section{REFERÊNCIAS}

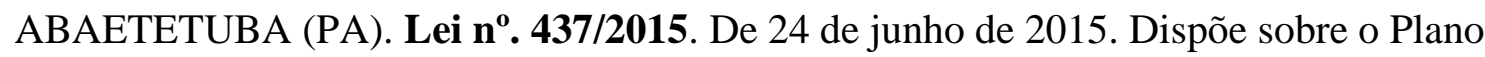
Municipal de Educação e dá outras providências. Abaetetuba. Disponível em: http://www.abaetetuba.pa.gov.br/arquivo/leis-municipais/2015-1/Lei\%20437\%202015.pdf. Acesso em: 03 jan. 2017.

ARRUTI, J. M.. Políticas Públicas para quilombos: terra, saúde e educação. In: Marilene de Paula e Rosana Heringer. (Org.). Caminhos Convergentes - Estado e Sociedade na Superação das desigualdades Raciais no Brasil. 1ed. Rio de Janeiro: Fundação Henrich Boll, Action Aid, 2009, v. 1, p. 75-110. Disponível em:http://www.boelllatinoamerica.org/downloads/caminhosconvergentes_03_jose_mauricio.p df. Acesso em: 25 set. 2016.

ASSEMBLEIA LEGISLATIVA DO PARÁ. Pedido de abertura do processo $\mathbf{N}^{\mathbf{0}}$ 000775/2007. Assembleia Legislativa do Pará, 2007.

\section{. GABINETE DA DEPUTADA NILMA LIMA. Memorando $\mathbf{N}^{\mathbf{0}} \mathbf{1 7 3 / 2 0 1 1}$.}

Encaminha convite aos vereadores de Moju (PA) e Abaetetuba (PA) para participar da reunião referente aos limites entre os dois municípios na Assembleia Legislativa do Pará após o Censo do IBGE em 2000 que redefiniu os limites municipais. Assembleia Legislativa do Pará: Belém, 02/12/2011.

BAUMAN, Zygmunt. Identidade: entrevista a Benedetto Vecchi. Tradução Carlos Alberto Medeiros. Rio de Janeiro: J. Zahar, 2005.

BELÉM (PA). Ofício no 179/2017 de 02/05/17. Ofício da Defensoria Pública para a Secretária de Educação do Municipal de Abaetetuba. 2017.

BRASIL. EMPRESA DE PLANEJAMENTO E LOGÍSITCA Brasília, DF, 2014. Concessões Ferroviárias. Brasília, DF, 2014. Disponível em:

<http://www.logisticabrasil.gov.br/ferrovias2>. Acesso em 25 jun. 2016. 
CARRIL, Lourdes de Fátima Bezerra. Quilombo, Território e Geografia. AGRÁRIA, São Paulo, No 3, 2006, pp. 156-171. Disponível em:

http://www.revistas.usp.br/agraria/article/view/92/91. Acesso em: 02 mai. 2017.

CRUZ, V. C. Movimentos sociais, identidades coletivas e lutas pelo direito ao território na Amazônia. In: Onildo Araújo da Silva; Edinuzia Moreia Carneiro Santos; Agripino Souza

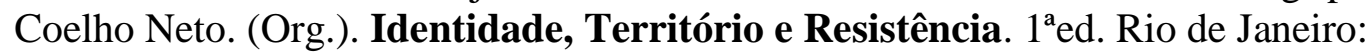

Consequência, 2014, v. 1, p. 37-72.

DEFENSORIA PÚBLICA DO ESTADO DO PARÁ. Núcleo de Direitos Humanos e Demandas Estratégicas. Ata da reunião realizada no dia 4 de maio de 2017. Livro -, p. 2.

FERNANDES, Bernardo Mançano. Movimentos socioterritoriais e movimentos socioespaciais: contribuição teórica para uma leitura geográfica dos movimentos sociais. Revista Nera - ano 8, n. 6 - janeiro/junho de 2005. Disponível em: http://revista.fct.unesp.br/index.php/nera/article/view/1460/1436. Acesso: 15 mai. 2017.

Os Campos da Pesquisa em Educação do Campo: espaços e territórios como categorias essenciais. In: MOLINA, Mônica Castagna. Educação do Campo e Pesquisa: questões para reflexão. Brasília: Ministério do Desenvolvimento Agrário, 2006. Disponível em:http://www.reformaagrariaemdados.org.br/sites/default/files/Educaçao.pdf. Acesso em: 15 mai. 2017. p. 27-39

FREIRE, P. A importância do ato de ler: em três artigos que se completam. 23. ed. São Paulo: Cortez, 1989.

. Pedagogia da autonomia: Saberes necessários à prática educativa. São Paulo: Paz e Terra, 1996.(Coleção Leitura)165 p.

HALL, Stuart. A identidade cultural na pós-modernidade. Tradução: Tomaz Tadeu da Silva, Guaracira Lopes Louro. 12. ed. Rio de Janeiro: Lamparina, 2015. 57 p.

Quem precisa da identidade? In: SILVA, T. T (Org) Identidade e diferença: a perspectiva dos estudos culturais. Petrópolis: Vozes, 2004.

HAESBAERT, Rogério. Identidades Territoriais. In: RODENDHAL, Zeny. CORRÊA, Roberto. Lobato. (Orgs.). Manifestações Culturais no Espaço. Rio de Janeiro: EDUERJ, 1999. p. $169-188$

INSTITUTO BRASILEIRO DE GEOGRAFIA E ESTATÍSTICA - IBGE. Ofício no 108/08 EU/PA-GAB de 10/04/08. Ofício do IBGE à Presidente do Tribunal Regional Eleitoral (TRE), 2008.

LEFEBVRE, Henri. A Produção do Espaço. Trad. Doralice Barros Pereira e Sérgio Martins do original: La production de l'espace. $4^{\mathrm{a}}$ ed. Paris: ÉditionsAnthropos, [2000].Primeira versão: fev. 2006. Disponível em: <http://www.mom.arq.ufmg. br/mom/arq_interface/1a_aula/A_producao_do_espaco.pdf>. Acesso em: 03 jan. 2017. 
Espaço e política: direito à cidade II. Tradução de Margarida M. de Andrade, Pedro H. Denski e Sérgio Martins. Belo Horizonte: Editora UFMG, 2016.

MARTINS, José de Souza. A chegada do estranho. São Paulo: Hucitec, 1993.

MOJU (PA). Lei no 844/2010; de 31 de maio de 2010. Dispõe sobre a criação do Plano Municipal de Educação do município de Moju. Disponível em: http://www.cmmoju.pa.gov.br/wp-content/uploads/2015/11/LEI-N\%C2\%BA-844-2010.pdf

NAÇÕES UNIDAS. OIT. Convenção 169, sobre povos indígenas e tribais e resolução referente à ação da OIT. Brasília: OIT, 2011.Disponível em:

http://portal.iphan.gov.br/uploads/ckfinder/arquivos/Convencao_169_OIT.pdf. Acesso em: 17 Jan. 2017.

PROMOTORIA DE JUSTIÇA DE ABAeTETUBA. Ministério Público. Ata da reunião realizada no dia 4 de maio de 2017. Livro -, p. 1-4.

SEDUC (PA). Lei $\mathbf{n}^{\mathbf{0}} \mathbf{7 . 8 0 6}$, de 29 de abril de 2014. Dispõe sobre a regulamentação e o funcionamento do Sistema de Organização Modular de Ensino - SOME. Secretaria Executiva de Estado de Educação - SEDUC, Belém: 29 abr. 2014. Disponível em:

http://www.pge.pa.gov.br/sites/default/files/lo7806.pdf. Acesso em: 23 Fev. 2017.

\section{Autor}

Carlos Alberto de Souza Mascarenhas - Possui Graduação em Geografia pela Universidade Federal do Pará (UFPA). Atualmente é Mestrando pelo Programa de Pós-Graduação em Geografia da Universidade Federal do Pará (UFPA) e professor da Secretaria Executiva do Estado do Pará (SEDUC).

Artigo recebido em: 30 de julho de 2017. Artigo aceito em: 29 de setembro de 2017. 